\title{
How Does the Type 2 Diabetes Mellitus Patients' Compliance to Managing Diabetics in Bangladesh
}

\author{
Umme Salma Mukta1, Umme Sayka², Pradip Sen Gupta ${ }^{3}$ \\ ${ }^{1}$ Research Associate, Research and Evaluation Division (RED), BRAC, Dhaka, Bangladesh \\ ${ }^{2}$ Monitoring and Evaluation Officer, Campaign for Population Education (CAMPE), Dhaka, Bangladesh \\ ${ }^{3}$ Adjunct Faculty, Department of Public Health, American International University of Bangladesh (AIUB) and \\ Associate, Department of Community Medicine, Bangladesh Institute of Health Sciences (BIHS), Dhaka, \\ Bangladesh \\ Email: salma.mukta@gmail.com
}

Received 7 November 2014; revised 15 December 2014; accepted 4 January 2015

Copyright $@ 2015$ by authors and OALib.

This work is licensed under the Creative Commons Attribution International License (CC BY).

http://creativecommons.org/licenses/by/4.0/

(c) (i) Open Access

\section{Abstract}

Introduction: According to an estimate of the World Health Organization, about 171 million people worldwide suffer from diabetes. But the incidence is increasing so rapidly that it is speculated that by 2030 this number will be almost doubled. Diabetes mellitus occurs all the way through the world, but it is becoming more common (especially type 2) in the developing countries. Due to rapid urbanization and changes of lifestyles, it is in the state of epidemiological shift. This study aimed to assess patients' compliance to treatment and whether it reduces the complication of diabetes, and its impact on overall management of diabetes. Objectives: The study objectives were to assess the compliances of diabetic's patients in terms of disease management \& to assess the association of patients' compliance with disease complexity. Methods: Mixed methods (qualitative \& quantitative) were used to conduct this study in Manikgong and Dhaka city. A pre-tested questionnaire was used for both methods. Quantitative data were collected by a structured questionnaire from 1830 participants of both sexes, and for the qualitative data a semi-structured questionnaire was used to conduct in-depth interview from 25 respondents and informal discussion was also organized with 8 care providers, i.e. physicians. Results: Findings revealed that very significant relation exists with compliances and complication in managing diabetes. That compliances influence by various factors like gender, education, occupation, treatment facilitates etc. But who followed the proper compliances faced fewer complications. In addition, compliances to herbal medicine were also familiar to diabetic patients. Most compliance as respondents preferred are: diet, exercise, weight control than the medication. Conclusion: Largely a optimistic outcome blowing that the patients (type 2 diabetes) who maintained appropriate compliances faced less complication than who didn't follow. 


\section{Keywords}

\section{Bangladesh, Compliances, Complications, Type 2 Diabetes}

\section{Subject Areas: Anthropology, Diabetes \& Endocrinology, Epidemiology, Public Health}

\section{Introduction}

Diabetes mellitus is recognized as a group of metabolic diseases while a person having high blood sugar, either because the body does not produce enough insulin or the cells don't respond to produced insulin [1]. World Health Organization estimated that, worldwide at least 171 million people suffer from diabetes [2]. Its incidence rate increases so rapidly that estimated that by 2030, the number will almost double, especially in Asia and Africa [3] [4]. Diabetes mellitus undoughtly achronic disease which is beyond cured except in very specific circumstances. Compliance concentrates to keep blood sugar levels as close to normal without experiencing hypoglycemia which can be easily done with regular diet, exercise, and use of appropriate medications [5]-[7].

Type 2 diabetes is the prevalent form disease from the very begining for its asymptomatic characteristic and remains undiagnosed for many years. A study found that approximately 5.4 million adults in the U.S. suffered from undiagnosed type 2 diabetes, who are under significant higher risk for coronary heart disease, stroke, and peripheral vascular disease than the non-diabetic people [8] [9]. These catagories of people have a greater likelihood experiencing dyslipidemia, hypertension, and obesity [4]. According to TheNational Diabetes Information Clearinghouse, in United State every year $\$ 132$ billion cost for diabetes treatment and the DALY (Disability adjusted life year) for diabetes was 2.8\%, per 100,000 inhabitants in 2004 [4] [9].

Considering this huge DALYs, Dr Mohammed Ibrahim, Professor of Medicine first thought of diabetic care in Bangladesh. He realized that diabetes is such a disease where not only doctors but patients should be involved in the process of diabetic care. Addressing the matter as socio-medical facts he established Bangladesh Institute of Research and Rehabilitation for Diabetes (BIRDEM). Presently BIRDEM, as the sister organization of Bangladesh Associassion of Diabetics Society (BADAS), efficiently and effectively provided services to the diabetic patients to reduce their complication, and to lower the prevalence rate one of the major non communicable diseases. There exists two types of compliance to reduce the complication of diabetes, they are:

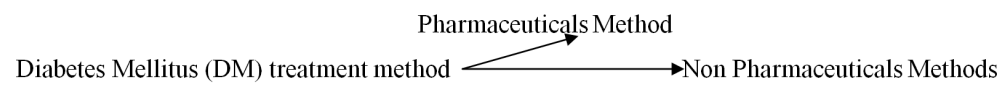

Diabetic patients do their own care (95\%), where physicians only play a collaborative role in the management system [10]. In Bangladesh diabetes yet reached the concerned area where it may suppose to reach. This study explored two basic research questions. These are: Is there a difference between patients' compliance to treatment and the complication of diabetes? Does patient compliance have any impact on the overall management of diabetes? The objectives of the study were to find out the role of patients' compliance in the management of types 2 diabetes mellitus, assess the association of patients' compliance with disease complexity and sort out the socio-demographic and other factors and its relation with patient's compliance (Figure 1).

\section{Methods}

\subsection{Study Design}

This study was utilized a mixed study design both qualitative and quantitative methods to adherences the comprehensive approaches. For that face to face in-depth interviews and key informant interview were conducted as a part of qualitative study. Participants were stratified to ensure homogeneity within different sex group. For quantitative part we selected a cross sectional design to assess the dietary consumption patterns and diversity of the participants' households. Data on socio-demographic variable and treatment option were also collected. 


\subsection{Site Selection}

The study was conducted in two settings: urban and rural area to compare the situation comprehensively. For urban settings BIRDEM (Bangladesh Institute of Research and Rehabilitation for Diabetes, Endocrine and Metabolic Disorders) and one of its sister institution were selected. BIRDEM the largest 600-bedded multidisciplinary hospital complex of the Diabetic Association of Bangladesh, situated at 129 New Eskaton Road, Dhaka district was selected. For rural settings Shibaloy Upazila of Manikgonj district was selected, which area is $1378.99 \mathrm{~km}^{2}$, under Dhaka District and situated in the east of the country. Here below the map showed that under the Dhaka Division the selected areas for the study were Shibaloy under Manikgonj District and BIRDEM from Dhaka District (Figure 2).

\section{Inclusion/Exclusion Criteria of the Participants}

\subsection{For Beneficiaries}

A) Inclusion Criteria: Participants aged 25 - 60 years, suffering from diabetes for last six months.

B) Exclusion Criteria: Participants with mental disabilities, who are visibly ill and those who are unable to

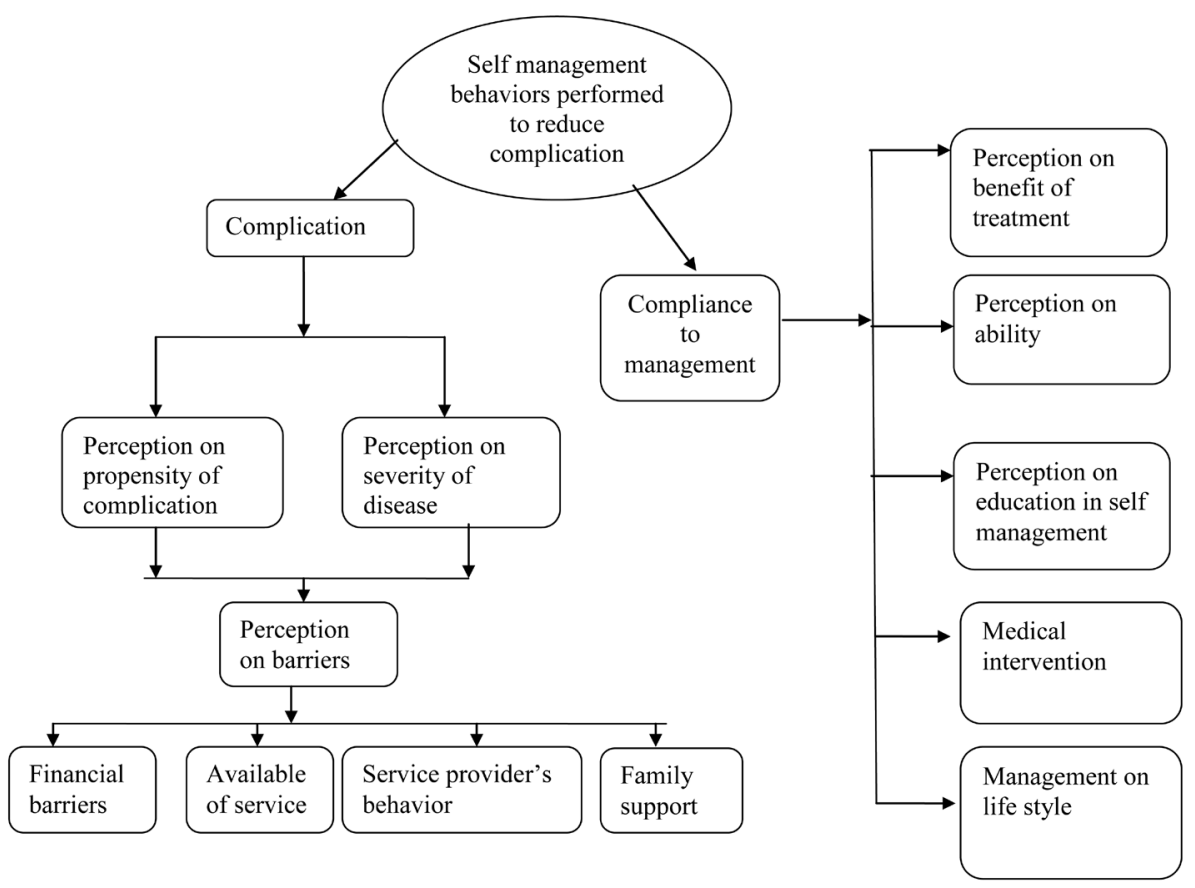

Figure 1. Conceptual framework.
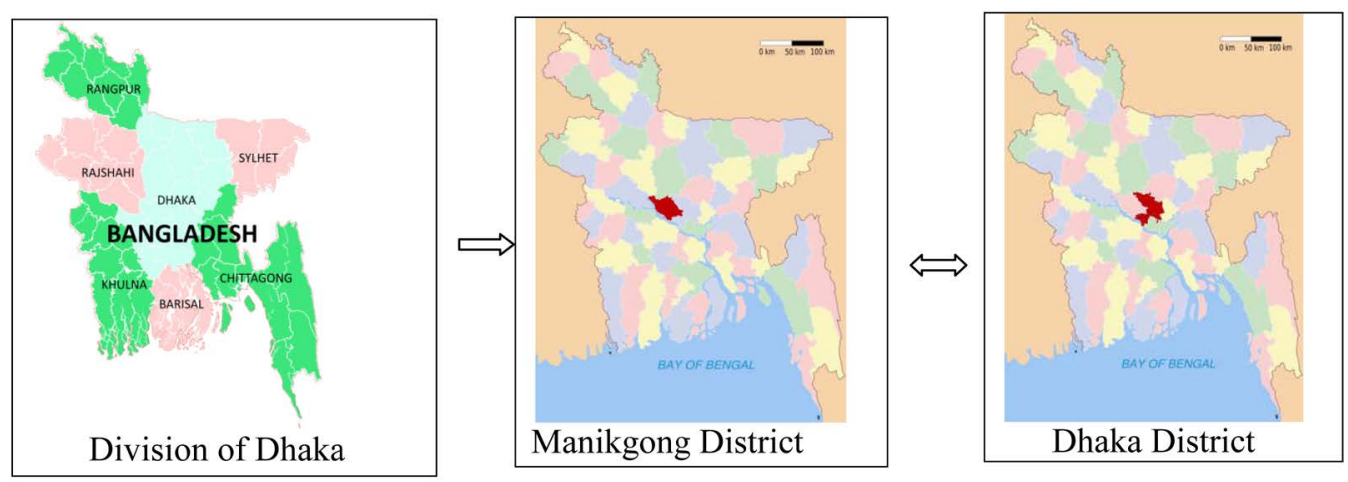

Figure 2. Study areas. 
comfortably participate for the interview were excluded from the study.

\subsection{For Facilitators}

A) Inclusion Criteria: between the ages of 25 - 60 years and serves the diabetic patients.

B) Exclusion Criteria: Service provider who refused to participate.

\subsection{Data Collection Tools and Technique}

We conducted 25 semi-structured in-depth interviews with patients and 8 key informant interview with physicians'. For the quantitative part a pre-coded structured questionnaire was applied to collect information from 1830 respondents (selected randomly), where 930 from urban (BIRDEM) and 900 from rural. It is estimated that around 500,000 patients' covered by BIRDEM where the daily turnover is around 2500 [11], from where we took more than $10 \%$ randomly. On the other hand for rural setting we followed the same sampling technique.

\subsection{Data Analysis}

For qualitative analysis we used thematic analysis. The transcribed data were coded and analysis was performed using Microsoft Office Excel, 2007, for qualitative analysis. For quantitative analysis all completed questionnaires were checked for inconsistency and errors before sending for analysis. After coding and cleaning of data, final analysis was done by using the SPSS 17.0 software.

\subsection{Ethical Considerations}

All data were entered and stored on password protected computer by the researcher. Only the primary investigator has access to this information. To ensure ambiguity of the participants, code was used to identify participants and groups in all stages of this research. Participants' names and other personal information were never be linked to their responses. All identifying information were modified when case studies cited in written reports. Ethical clearance was approved by the respective institutions and a written consent taken from the participants before data collection.

\subsection{Data Collection Period}

The data was collected during the period from November, 2011 to January, 2012 and from proposal developed to report writing it takes around 6 months.

\section{Results}

From the study finding data were presented below

Table 1 shows that around half of respondents in both urban and rural areas were aged within 47 to 61 years which in was $49.2 \%$ average. The proportion of age group category less than 31 was lowest in both urban (2.4\%) and rural (4.2\%) area total of $6.6 \%$. About $13 \%$ had no formal education among both areas. A great majority (32.6\%) of them passed primary level of education (here we consider class VI-X). Second higher level was tertiary level was $25 \%$ (here consider graduate and masters) in both areas.

Vast majority of them were married which is almost $87 \%$. The percentages of widow, unmarried were pretty much higher among the rural area's respondents' comparing to the urban area. Both areas we found vast majority were Muslim. The second higher religion category was Hindu. According to the occupational category majority of female were housewife and male were service holders. The next occupational category belongs to business. Fewest people from the respondent were retired from their job.

Here Table 2 shows that most of respondents (97.3\%) were informed about their diabetes from the health professionals like doctor, nurse, other health care providers etc. Rest of the respondents in urban area checked by own selves either from a pathology or medicine shop. Rural respondents had no idea about their diabetes status but incidentally diagnosed during other medical checkup.

From the qualitative part of study we found that most of the respondents at first couldn't identify their diabetes status because of their poor knowledge on signs and symptoms of the diseases. Whenever they noticed any symptoms of diabetes they simply ignored it until they developed complications when they go to doctor for 
Table 1. Summary of socioeconomic profile of respondents.

\begin{tabular}{|c|c|c|c|}
\hline \multirow{2}{*}{ Study variables } & \multicolumn{3}{|c|}{ Study areas \% } \\
\hline & Urban $(n=930)$ & Rural $(\mathrm{n}=900)$ & All $(n=1830)$ \\
\hline \multicolumn{4}{|l|}{ Age } \\
\hline$<31$ & 2.4 & 4.2 & 6.6 \\
\hline $32-46$ & 15.1 & 18.2 & 33.3 \\
\hline $47-61$ & 28.8 & 20.4 & 49.2 \\
\hline $62^{+}$ & 6.3 & 4.6 & 10.9 \\
\hline \multicolumn{4}{|l|}{ School education } \\
\hline No education & 8.9 & 4.3 & 13.2 \\
\hline Pre-Primary (I-IV) & 3.2 & 2.3 & 5.5 \\
\hline Primary (VI-X) & 15.1 & 17.5 & 32.6 \\
\hline Secondary (XI-XII) & 12.9 & 10.1 & 23.0 \\
\hline Graduate and Above & 8.5 & 16.6 & 25.1 \\
\hline Madrasha education & 0.6 & 0 & 0.6 \\
\hline \multicolumn{4}{|l|}{ Marital status } \\
\hline Unmarried & 1.1 & 2.8 & 3.9 \\
\hline Married & 48.7 & 37.8 & 86.5 \\
\hline Widow/witch & 1.9 & 3.5 & 5.4 \\
\hline Divorced/Separated & 1.5 & 2.7 & 4.2 \\
\hline \multicolumn{4}{|l|}{ Religion } \\
\hline Islam & 53.3 & 34.1 & 87.4 \\
\hline Hindu & 2.3 & 4.7 & 7.0 \\
\hline others & 0 & 5.6 & 5.6 \\
\hline \multicolumn{4}{|l|}{ Occupation } \\
\hline Sewing & 0.6 & 0.6 & 1.2 \\
\hline Labor & 1.8 & 1.2 & 3.0 \\
\hline Service holders & 11.9 & 11.3 & 23.2 \\
\hline Business & 6.1 & 7.6 & 13.7 \\
\hline Teacher & 1.2 & 1.2 & 2.4 \\
\hline Retire & 3.0 & 5.0 & 8.0 \\
\hline Housewife & 23.9 & 22.9 & 46.8 \\
\hline Unemployed & 1.7 & 0 & 1.7 \\
\hline
\end{tabular}

Table 2. Sources of information about disease status i.e., diabetes.

\begin{tabular}{|c|c|c|c|c|}
\hline \multirow{2}{*}{ Area } & \multicolumn{3}{|c|}{ Sources of information on diabetes from any physicians } & \multirow{2}{*}{ Total } \\
\hline & Yes & No & Unknown & \\
\hline Urban & $49.2 \%$ & $1.6 \%$ & $0.0 \%$ & $50.8 \%$ \\
\hline Rural & $48.1 \%$ & $0.0 \%$ & $1.1 \%$ & $49.2 \%$ \\
\hline Total & $97.3 \%$ & $1.6 \%$ & $1.1 \%$ & $100.0 \%$ \\
\hline
\end{tabular}


treatment and then they knew about their diabetes.

One patient said that, "At first I simply ignored the physical problem like sweating, excessive urination and others. But when I had some more problems I went to nearest doctor and to tell my symptoms, the doctor suggested for some blood test and then I could know about my diabetes. But I couldn’t belief it at first, ignored to maintain doctor's advices."

Even after knowing about their diabetes some respondents didn't take any treatment. So we analyzed the data according to the following pathways to see the compliances. Here we considered compliances according to patients' perception of their health outcome and their practices of various treatment methods.

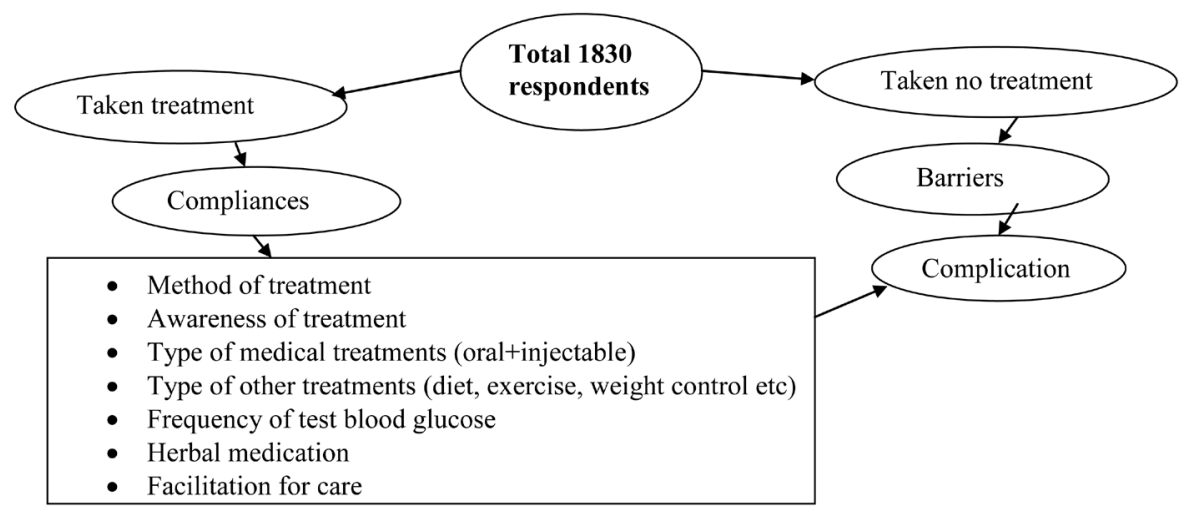

Table 3 shows the $93.4 \%$ percentages of respondents took medicine or other methods of treatment to control diabetes as per their perception. For the qualitative part we found that the most of the respondents in urban were conscious and knew about diabetes and so as early they knew about diabetes they started treatments and maintained various compliances. In past the rural people ignored it, but now a day's the people's awareness increased and so they were more conscious about treatment.

Table 4 shows vast majority from both areas took medicine regularly (in urban $74 \%$ and rural $86 \%$ ). As a second option both in urban (46\%) and in rural (36\%) are as participants' emphasize on controlling diet. The next group of respondents took a comprehensive exercise and the proportion was in total of $62 \%$. Few (8\%) from urban and some from (17\%) rural mentioned about weight controlling as a method. A few number from both areas mentioned about insulin because of non-availability and expenses of insulin.

Table 3. Distribution of respondents who took medicine after knowing their diabetics.

\begin{tabular}{ccccc}
\hline Took Medicine & Yes & No & Unknown & Total \\
\hline Area & $48.6 \%$ & $2.2 \%$ & $0 \%$ & $51 \%$ \\
Urban (\% of Total) & $44.8 \%$ & $3.8 \%$ & $0.5 \%$ & $49 \%$ \\
Rural (\% of Total) & $93.4 \%$ & $6.0 \%$ & $0.5 \%$ & $100 \%$ \\
\hline
\end{tabular}

Table 4. Distribution method of treatment followed by respondents (found mostly multiple responses).

\begin{tabular}{ccc}
\hline Cases & Urban area \% & Rural area \% \\
\hline After knowing diabetes took diet regularly & $\mathbf{4 6 . 2}$ & $\mathbf{3 5 . 6}$ \\
After knowing diabetes took exercise regularly & 34.4 & 27.8 \\
After knowing diabetes took medicine regularly & $\mathbf{7 4 . 2}$ & $\mathbf{8 5 . 6}$ \\
After knowing diabetes took initiation to control weight & 7.5 & 16.7 \\
After knowing diabetes took insulin & 4.3 & 1.1 \\
After knowing diabetes no method taken at all. & 4.3 & 5 \\
\hline
\end{tabular}


Qualitative finings revealed that after knowing about diabetes most of the people preferred for physical exercise which cost nothing for them. Then they go for diet, weight control, and medication. For the poor country like Bangladesh to bear medication cost is not affordable to all. So people at first preferred for low cost medication. They also preferred exercise like walking, house-hold works, and physical activities. For medication they preferred for herbal drugs which is less expensive. So consumption of insulin found to be very rare in rural area.

On the other hand around 58\% female and 95\% male respondents followed more than one method of treatment. The number was high among male in rural than all other category. Mostly they preferred physical exercise like walking, regular diet, intake low fat, ruti (homemade bread) as two main meals, fruits and vegetables etc. Only 19\% from total respondents following only single measure to control like either diet or exercise or weight control etc where regular exercise and diet got most priorities.

Table 5 shows the relation of any compliance to controlling diabetes within difference age group category. Among the different age category most of the respondents belongs to aged 47 - 61 years and they preferred (43.72\%) taking any type of compliances method to controlling diabetes. Interestingly it has been found that $3.28 \%$ respondents in this age group did not follow any treatment regimen which is also high in this age group. The nearest age categories who were aware about compliances to controlling diabetics was 32 - 46 years groups (33.88\%) followed by the age group below 31 years (5.46\%) and above 62 years (10.38\%).

Table 6 shows that among the respondents the frequency of compliances was high who had primary level of education (28.96\%). Non compliance with treatment also high in this group compared to other educational attainment group (2.73\%). The second major category is from graduate level of education (24.59\%).

Table 7 shows the changes of health status following treatment compliance i.e., vast majority (97.4\%) of them told that they felt better than the previous time. The second majority (98.2\%) of them told that they now live better. Some (95\%) also told that they can now do usual normal work smoothly like previous time. Almost all of them also told that they now had less discomfort, no weakness and no urination problem and no sweating

Table 5. Relation with age and compliances (\%).

\begin{tabular}{ccccccc}
\hline & \multicolumn{3}{c}{ Age } & & Total \\
\cline { 2 - 5 } Treatment & $>31$ & $32-46$ & $47-61$ & $62+$ & & 93.44 \\
yes & $\mathbf{5 . 4 6}$ & 33.88 & 43.72 & 10.38 & 6.01 \\
no & 0.55 & 2.19 & 3.28 & 0 & 0.55 \\
unknown & 0 & 0 & 0 & 0.55 & 1.09 & 100 \\
\hline
\end{tabular}

Table 6. Relation with compliances to education of the respondents (\%).

\begin{tabular}{ccccccccc}
\hline & & & & & \multicolumn{2}{c}{ Education } \\
\cline { 3 - 7 } & & Illiterate & Pre primary & Primary & Secondary & Graduate & Madrasha \\
\hline \multirow{2}{*}{ Treatment } & yes & 10.93 & 5.46 & $\mathbf{2 8 . 9 6}$ & 22.95 & 24.59 \\
& no & 1.64 & 0.55 & 2.73 & 0 & 0 \\
& unknown & 0.55 & 0 & 0 & 0 & 0 \\
\hline
\end{tabular}

Table 7. Changes of Health Status following treatment compliances (\%).

\begin{tabular}{|c|c|c|c|c|c|}
\hline $\begin{array}{c}\text { Feel better than } \\
\text { previous }\end{array}$ & Improved disease status & Better living & Can do normal work & $\begin{array}{c}\text { No weakness \& frequent } \\
\text { urination }\end{array}$ & No Sweating \\
\hline 97.4 & $100 \%$ & 98.2 & $95 \%$ & 100 & 100 \\
\hline \multicolumn{6}{|c|}{ Changes due to follow following treatment (\%) } \\
\hline Balance diet & Exercise & Weight control & Oral medicine & Insulin & Herbal therapy \\
\hline 38.25 & 28.96 & 11.46 & 71.04 & 27.32 & 2.19 \\
\hline
\end{tabular}


problem. They believe these positive changes occurred because of taking a balanced diet (38.25\%) and doing other activities like physical and mental exercise suggested by physician's (28.96\%), regular exercise including yoga and some free hand exercise to weight control (11.46\%), intake of oral medication (71.04\%), intake of inject able medication (27.32\%), intake of some herbal medication like dry seed (black berry), Noyontara flower (China rose), roots (2.19\%), etc.

\section{Problems Perceived by Respondents Due to Not Taking Any Treatment}

The qualitative finding of the study revealed that some patients who did not take any treatment faced some difficulties for controlling diabetes. Majority mentioned that they mainly faced eye problem. Others mentioned that their blood glucose is not stable and increases and they also noticed accumulation of fluid in the whole body. Though few of them said that they have no problems but they were not fairconfident about their remarks. Other complications respondent perceived on sweating, weakness, obesity, and fluctuation of blood glucose as previous etc.

\section{Discussion}

Type 2 diabetes increases with age and nearly 27\% of people in the United States older than 65 years have diabetes [12] Other studies showed that high incidence rate of type 2 diabetes relatively found among young population [13] [14]. In Iran it is estimated that each year more than 310 thousands individuals develop type 2 diabetes [15] [16]. This study also revealed that the proportion of type-2 diabetics was high among the age group of 47 - 61 which was $49 \%$ in total and also 32 - 46 years a group was $33 \%$. From this study it is also revealed that a significant portion of population in Bangladesh who suffered from diabetes was in between older age and near to middle age and after 45 the ratio is increased. In our study most of the participants ( $>90 \%)$ went to health care provider to diagnose their disease status, in urban area it was $49 \%$ and in rural area it was $45 \%$.

Management of Type 2 diabetes consists of a combination of diet, exercise, and weight loss, in any achievable combination depending on the patient to control type 2 diabetics. Obesity is very common in type 2 diabetes which contributes mostly for insulin resistance. Patients with poor diabetic control after lifestyle modifications are typically placed on oral hypoglycemics. Some type 2 diabetics eventually fail to respond to these and lead to insulin therapy. By weight reduction and exercise the tissue sensitivity can be improve to allow its proper use by target tissues [17] [18].

Some studies showed that within three weeks with the rigorous diet and exercise can brought dramatic improvement for diabetics and pre-diabetics patients [19]-[21]. From this study we also found that after advice given by professional physician's on diet was the first priority as compliances among the patients which were $46 \%$ in urban area and $36 \%$ in rural area.

From our study we found that most people with type 2 diabetes mellitus are active, although they are not enought confident about that regular physical activity may prevent or postpone the onset of diabetes and the complications of diabetes. Almost 93\% patients preferred exercise (mostly walking) as compliance to controlling diabetics which is incuring no extra cost for them. Other studies also revailed that by achieving and maintaining a healthy weight diabetes can be well controlled and reduces other complications of diabetes [15] [22]-[26].

From this study it was found that weight control method for controlling diabetics was used by $43 \%$, participants which was higher in urban area. According the urban area people were more aware about obesity and its effect and so they were more conscious on weight control in addition to diet and exercise. This finding may point to the strong association of type 2 diabetes with in appropriate compliances in the Bangladeshi population.

The importance of management of type 2 diabetes with pharmacologic and non-pharmacologic therapies varies in cost and risk [27]. A study found that among the diagnosed people 14\% take both insulin and oral medication and 58\% take oral medications only [28] [29]. In our study we found the intake of oral medication was $89 \%$ and for inject able medication only 50\%. Here also the insulin intake was high in urban area due to cost and availability of the drug in local market. Around 24\% respondents we found took herbal medications for controlling diabetics which is lower in cost.

Many physicians appear unwilling or cautious about prescribing exercise to individuals with type 2 diabetes 
for a variety of reasons; such as excessive body weight or the presence of health-related complications [15] [30]. But in our study we found that physicians were more likely prefer to do laboratory test for acessing the status of diabeties and prescribed drug then other methods. Only we found that the BIRDEM hospital provided each of its patients a guide book where age specific instructions for diet (with picture messages for illiterate persons), provide free classes for nutritional education and demostrate free hand exercise. But unfortunately these sessions not reachable to all patients due to certain valied reasons. Also the complication for inappropriate compliances, obesity, and weight control etc were not illustrated precisely to the patients. Guidelines for women who are pregnant or lactating or who wish to become pregnant, as well as all individuals aged 50 years or older, are also available there.

Education of patients and compliance with treatment is very important in managing the disease. Improper use of medications and insulin can be very dangerous causing hypo- or hyper-glycemic episodes which also influenced by lack of knowledge about excersise, diet and weight loss [31] [32]. This study also found that among the educated people the compliance rate was highly significant than the illitarate or littile education on its importance and effect.

Barriers found to follow the compliances among the respondents were the financial problem to follow treatment regimen. Culture is often defined as a learned set of values, beliefs, norms, and patterns of behavior. Diabetes is often believed to be caused by eating excess sweets (particularly sugar), brought on by stress and worry, or a form of punishment for immoral behavior. Often patients who do not practice healthy behaviors and don't care about their health mostly suffered from diabetes. The second set of barriers: those of the health care system include issues of service availability, accessibility, and acceptability. Issues of availability traditionally include service/facility location, the number and type of providers in the facilities, and whether services are known to the disadvantage populations.

\section{Conclusion}

Special attention in terms of preventive strategies with abnormal glucose tolerance was needed for the patients, as this state was the most prominent for type 2 diabetes. Exercise, diet and weight loss can provide tremendous benefits to both body and soul at any age. It is therefore important to ensure that it is done properly and safely. Type 2 diabetes usually appears in people over the age of 45 , but it is also increasingly becoming more common in children, adolescents and young people. So it is a prime need to build awareness on proper compliances and that should be maintained from the very beginning after accurate diagnosis of diabetes

\section{Conflicts of Interest}

The authors declare that they have no conflicts of interest.

\section{Contributions}

All authors were equally involved in the conceptualization and design of the study. Umme Salma Mukta (USM) led data collection, analysis and interpretation with substantive inputs from Umme Sayka (US) and Pradip Sen Gupta (PSG). The paper developed with substantive input from US and PSG.

\section{Acknowledgements}

At first our thanks goes to Almighty Allah by whose blessing we are all right to did the job successfully. The authors place gratefulness to the Dean of Arts and Social Sciences Faculty (MPH programme) Prof. MdTazul Islam for his kind support. Then our warm regards goes to all the staff and the local implementing partners of Diabetes Association of Bangladesh (DAB) to arrange the voluntary participation for this study. We also appreciate the assistance provided by AIUB colleague and Office team. The authors heartily appreciate the assistance provided by research assistants for their good work and help me in data collection: Al Mamun, Rahima Akter, Saida Khan, Sayema Akter, Bithi Nandi, Bijoy Shangkar Barua and Sukanto Paul. Our warm thanks go to my colleague of BRAC for their advice, thoughtful suggestions and cooperation. Finally, the authors thank the entire respondent who actively participated in the interviews and expressed their views. Funding was provided by own sources of the Principle Investigator. 


\section{References}

[1] Lawrence, J.M., Contreras, R., Chen, W.S. and Sacks, D.A. (2008) Trends in the Prevalence of Preexisting Diabetes and Gestational Diabetes Mellitus among a Racially/Ethnically Diverse Population of Pregnant Women, 1999-2005. Diabetes Care, 31, 899-904. http://dx.doi.org/10.2337/dc07-2345

[2] Elizabeth, D., et al. (2008) Type 2 Diabetes Overview. Web MD. Step-Up to Medicine (Step-Up Series). http://diabetes.webmd.com/guide/type-2-diabetes.

[3] Lambert, P. (2002) What is Type 1 Diabetes? Medicine, 30, 1-5. http://dx.doi.org/10.1383/medc.30.1.1.28264

[4] American Diabetes Association (ADA) (2005) Other “Types” of Diabetes. http://www.diabetes.org/other-types.jsp

[5] Wild, S., et al. (2004) Global Prevalence of Diabetes: Estimates for 2000 and Projections for 2030. Diabetes Care, 27, 1047-1053. http://dx.doi.org/10.2337/diacare.27.5.1047

[6] Santaguida, P.L., et al. (2008) Diagnosis, Prognosis, and Treatment of Impaired Glucose Tolerance and Impaired Fasting Glucose. Summary of Evidence Report/Technology Assessment, No. 128. Agency for Healthcare Research and Quality. http://archive.ahrq.gov/clinic/epcsums/impglusum.htm

[7] Nathan, D.M., et al. (2005) Intensive Diabetes Treatment and Cardiovascular Disease in Patients with Type 1 Diabetes. The New England Journal of Medicine, 353, 2643-2653. http://dx.doi.org/10.1056/NEJMoa052187

[8] USDA. Dietary Guidelines for Americans, 2010. Released January 31, 2011.

[9] CDC’s Diabetes Program-News and Information-Press Releases-October 26, 2000. http://www.cdc.gov/Diabetes/news/docs/010126.htm

[10] Cooke, D.W. and Plotnick, L. (2008) Type 1 Diabetes Mellitus in Pediatrics. Pediatrics in Review, 29, 374-384; quiz 385. http://dx.doi.org/10.1542/pir.29-11-374

[11] Saleh, F., Ahmed, K.R., Rashid, I.B., Akter, F., Hannan, J.M.A., Ali, L., Rahman, M., Mannan, S. and Thilsted, S. (2005) Evaluation of the Levels of Knowledge, Attitude and Practices of Bangladeshi Type 2 Diabetic Subjects. Diabetes and Endocrine Journal, 33, 24-27.

[12] National Diabetes Information Clearinghouse (NDIC) (2008) Diabetes Overview. NIH Publication No. 09-3873. http://diabetes.niddk.nih.gov/dm/pubs/overview/

[13] Booth, F.W. and Chakravarthy, M.V. (2006) Physical Activity and Dietary Intervention for Chronic Diseases: A Quick Fix after All? Journal of Applied Physiology, 100, 1439-1440.

[14] Roberts, C.K., Won, D., Pruthi, S., Kurtovic, S., Sindhu, R.K., Vaziri, N.D. and Barnard, R.J. (2005) Effect of a Short-Term Diet and Exercise Intervention on Oxidative Stress, Inflammation, MMP-9, and Monocyte Chemotactic Activity in Men with Metabolic Syndrome Factors. Journal of Applied Physiology, 100, 1657-1665.

[15] Bhattacharya, S. (2006) Three-Week Diet Curbs Diabetes. New Scientist, 13 January 2006. Journal of American Diabetics.

[16] American Diabetes Association (2010) Total Prevalence of Diabetes \& Pre-Diabetes. Alexandria. Archived from the Original on 2006-02-08.

[17] Garg, A., Bantle, J.P., Henry, R.R., Coulston, A.M., Griver, K.A., Raatz, S.K., et al. (1994) Effects of Varying Carbohydrate Content of Diet in Patients with Non-Insulin-Dependent Diabetes Mellitus. JAMA, 271, 1421-1428.

[18] Kricht, T.G., Anderson, J.W. and Ward, K. (1976) Beneficial Effects of a High Carbohydrate, High Fiber Diet on Hyperglycemic Diabetic Men. American Journal of Clinical Nutrition, 29, 895-899. http://www.ajcn.org/cgi/content/abstract/29/8/895

[19] Bantle, J.P., et al. (2006) Nutrition Recommendations and Interventions for Diabetes-2006: A Position Statement of the American Diabetes Association. Diabetes Care, 29, 2140-2157. http://dx.doi.org/10.2337/dc06-9914

[20] Yuzo, S. (2006) New Timea of the Diabetes Mellitus Treatment. Treatment. Diet Therapy and Exercise Therapy. Japanese Journal of Clinical and Experimental Medicine, 83, 25-29. http://sciencelinks.jp/j-east/article/200604/000020060406A0084331.php

[21] Penny Murata, M.D. (2010) New Guidelines for Exercise in Type 2 Diabetes. CME, Pub Med, Journal of CME PMID: 17593642.

[22] Valdes, S., Botas, P., Delgado, E., Álvarez, F. and Diaz Cadórniga, F. (2007) Population-Based Incidence of Type 2 Diabetes in Northern Spain: The Asturias Study. Diabetes Care, 30, 2258-2263. http://dx.doi.org/10.2337/dc06-2461

[23] Unwin, N., Shaw, J., Zimmet, P. and Alberti, K.G. (2002) Impaired Glucose Tolerance and Impaired Fasting Glycaemia: The Current Status on Definition and Intervention. Diabetic Medicine, 19, 708-723. http://dx.doi.org/10.1046/j.1464-5491.2002.00835.x

[24] Wang, J.J., Yuan, S.Y., Zhu, L.X., Fu, H.J., Li, H.B., Hu, G. and Tuomilehto, J. (2004) Effects of Impaired Fasting Glucose and Impaired Glucose Tolerance on Predicting Incident Type 2 Diabetes in a Chinese Population with High 
Post-Prandial Glucose. Diabetes Research and Clinical Practice, 66, 183-191. http://dx.doi.org/10.1016/j.diabres.2004.03.002

[25] Ghassemi, H., Harrison, G. and Mohammad, K. (2002) An Accelerated Nutrition Transition in Iran. Public Health Nutrition, 5, 149-155. http://dx.doi.org/10.1079/PHN2001287

[26] Alexander, G.C., Sehgal, N.L., Moloney, R.M. and Stafford, R.S. (2007) National Trends in Treatment of Type 2 Diabetes Mellitus, 1994-2007. Archives of Internal Medicine, 168, 2088-2094.

[27] Centers for Disease Control and Prevention (CDCP) (2011) National Diabetes Fact Sheet: National Estimates and General Information on Diabetes and Prediabetes in the United States, 2011. U.S. Department of Health and Human Services, Centers for Disease Control and Prevention, Atlanta.

[28] De Vegt, F., Dekker, J.M., Jager, A., Hienkens, E., Kostense, P.J., Stehouwer, C.D.A., et al. (2001) Relation of Impaired Fasting and Postload Glucose with Incident Type 2 Diabetes in a Dutch Population: The Hoorn Study. JAMA, 285, 2109-2113. http://dx.doi.org/10.1001/jama.285.16.2109

[29] Zimmet, P., Alberti, K.G. and Shaw, J. (2001) Global and Societal Implications of the Diabetes Epidemic. Nature, 414, 782-787. http://dx.doi.org/10.1038/414782a

[30] Azizi, F., Rahmani, M., Emami, H., Mirmiran, P., Hajipour, R., Madjid, M., et al. (2002) Cardiovascular Risk Factors in an Iranian Urban Population: Tehran Lipid and Glucose Study (Phase 1). Sozial- und Präventivmedizin, 47, 408-426; Report of the Expert Committee on the Diagnosis and Classification of Diabetes Mellitus. Diabetes Care, 20, 11831197.

[31] Bozorgmanesh, M.R., Hadaegh, F., Padyab, M., Mehrabi, Y. and Azizi, F. (2008) Temporal Changes in Anthropometric Parameters and Lipid Profile According to Body Mass Index among an Adult Iranian Urban Population. Annals of Nutrition and Metabolism, 53, 13-22. http://dx.doi.org/10.1159/000152869

[32] Barnard, N.D., Katcher, H.I., Jenkins, D.J.A., Cohen, J. and Turner-McGrievy, G. (2009) Vegetarian and Vegan Diets in Type 2 Diabetes Management. Nutrition Reviews, 67, 255-263. http://dx.doi.org/10.1111/j.1753-4887.2009.00198.x 


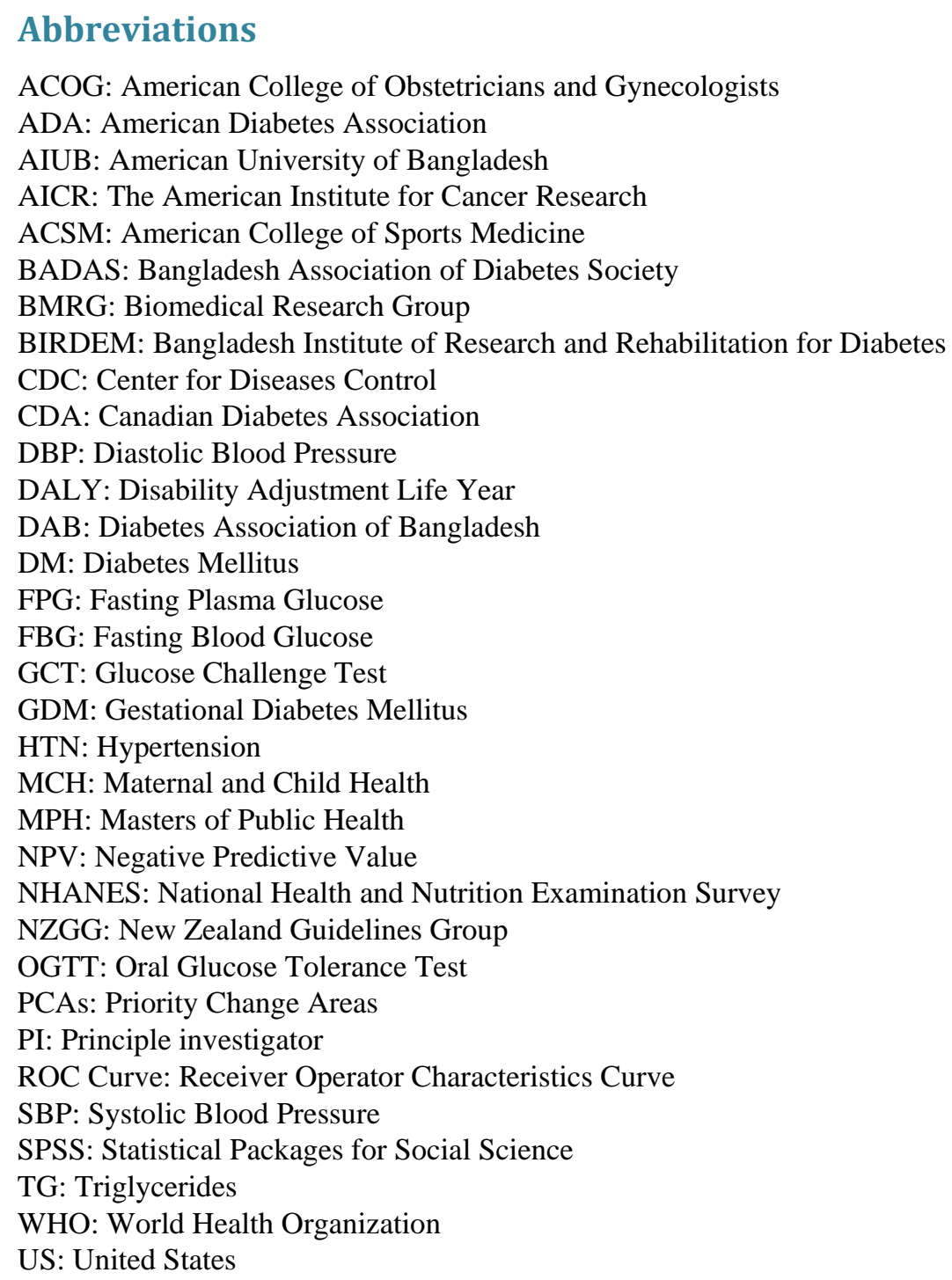

